\title{
Effect of Different Temperatures on the Life Table Parameters of Rhyzobius Lophanthae Blaisdell (Coleoptera: Coccinellidae)
}

Ali KAYAHAN ( $\square$ aalikayahan@gmail.com )

Yozgat Bozok University

Qasim Hussein AHMED

University of Baghdad

İsmail KARACA

Isparta University of Applied Sciences

\section{Research Article}

Keywords: Coccinellids, Rhyzobius lophanthae, Life table parameters, Optimum temperatures

Posted Date: December 28th, 2021

DOI: https://doi.org/10.21203/rs.3.rs-1169331/v1

License: (1) (i) This work is licensed under a Creative Commons Attribution 4.0 International License.

Read Full License 


\section{Abstract}

The purple scale predator, Rhyzobius lophanthae Blaisdell (Coleoptera: Coccinellidae) is known as coccidophagous ladybird predator, and effective against scales' insects. The present study aimed to evaluate the optimum temperature for the species to be more efficient. In this study, the life table parameters of $R$. lophanthae were determined on different temperatures at $4,16,18,20,22,24,26,28,30$ and $32{ }^{\circ} \mathrm{C}$ and $60 \% \mathrm{RH}$, by calculations using RmStat-3 software according to Euler-Lotka equation. The results showed that the intrinsic rates of increase $\left(r_{m}\right)$ were $0.016,0.022,0.030,0.052,0.056,0.068,0.120$, $0.142,0.132,0.021$ females/females/day, respectively, while the net reproductive rates $\left(R_{0}\right)$ were 7.082 , $9.514,11.960,50.906,54.150,49.525,56.883,80.944,31.149,1.882$ females/females/generation, respectively. The mean generation times $\left(T_{0}\right)$ were $125.966,104.602,84.009,75.742,71.511,57.568$, $33.801,30.866,25.978,30.759$ days, respectively. Total productivity rates (GRR) were 34.865, 39.210, 48.216, 201.990, 209.469, 166.207, 177.779, 303.751, 105.751, 12.622 egg/female, respectively. The study concluded that $26-30^{\circ} \mathrm{C}$ was the optimum temperature range for the efficient role of $R$. lophanthae under laboratory conditions. From the results, it is still needed to do more studies on the interactions of pests, predators with environmental conditions.

\section{Introduction}

Citrus trees production in Turkey has been affected by different insect pests including scale insects that have been increased recently. For controlling such pests, the intensive use of chemical pesticides has led to decrease the role of natural enemies; caused pesticides residues in the agricultural productions, environmental pollution and negative effects on human health. Producers of citrus have preferred to use various methods and reduce pest populations. Biological control is one of these methods and can be a promise way to control pests (Uygun \& Karaca, 1998). The purple scale predator, Rhyzobius lophanthae Blaisdell (Coleoptera: Coccinellidae) is known as an important coccidophagous ladybird predator and very effective against soft scales insects and is frequently observed in citrus and other fruit orchards where scale insects are present (Branco et al., 2017). R. lophanthae is native to Australia and has distributed too many regions of the world as a biological control agent (Hodek \& Honek, 1996). The predator has been reported on many countries, except Turkey as an important biocontrol agent of scale insects (Stathas et al., 2002; Mellado, 2011). As reported in many studies the development and efficacy of many predator and parasitoid insects are affected by temperature (Luhring et al., 2019; Gao et al., 2020; Kayahan \& Karaca, 2020). The present study aimed to evaluate the effect of 10 different temperatures on the life table parameters of predator, $R$. lophanthae under laboratory conditions.

\section{Materials And Methods}

\section{Culture of Aspidiotus nerii Bouché}

Aspidiotus nerii was used as a prey in the present study. The culture of soft scale insect was obtained from the mass production at the laboratory from Biological Control Research and Application Center, 
Faculty of Agriculture, Isparta University of Applied Sciences, Turkey. The A. nerii was continued reproductive in weekly periods of the study. A. nerii was reared on potato tubers (Solanum tuberosum L.). Infested potato tubers with $A$. nerii were placed on the clean potatoes for increasing the population culture of the pest to be used in experiments.

\section{Culture of Rhyzobius lophanthae}

Rhyzobius lophanthae samples were collected from citrus orchards in Adana Province located in Turkey. The predators were collected, using shaking method of the infested citrus branches. A laboratory colony of $R$. lophanthae was raised under incubator chamber at $25 \pm 1^{\circ} \mathrm{C}, 65 \pm 5 \% \mathrm{RH}$ with $16 \mathrm{~L}$ : $8 \mathrm{D}$ light conditions at the Department of Plant Protection, Isparta University of Applied Sciences, Turkey. The predator individuals were used as a stock culture for experiments.

\section{Experimental design}

This study was carried out in incubators that set up on 10 different temperatures degrees $(14,16,18,20$, $22,24,26,28,30$ and $32^{\circ} \mathrm{C}$ ), and $60 \% \mathrm{RH}$ with a light period of (16L: 8D). Fresh $40 \mathrm{R}$. lophanthae adults (20 male, 20 female) newly emerged from pupae were collected. Then, all adults were placed on the potato tubers infested with $A$. nerii and left in a plastic container ( $9 \times 9 \times 5 \mathrm{~cm}$ dimensions). After rearing 20 pairs of the predator for 15 days on potatoes under the laboratory conditions, the eggs laid by the predator on potato tubers were collected by using a soft sable brush to avoid damaging the eggs. Each egg was placed on an infested potato tuber using a soft brush. Then, the larvae of $R$. lophanthae, were exposed to different temperatures until the adult stage. The experiment was continued with the pairs formed after the emergence of adult individuals from the pupae. For this purpose, female and male individuals were left on each potato infested with A. nerii depending on the temperature. After this process, daily checks of the replicates were made. Daily number of eggs deposited by female individuals was determined and the trials continued until the last predator died. Life tables' parameters of $R$. lophanthae at each temperature were recorded based on the data obtained. Replicates were examined daily under a stereomicroscope (Leica S6D) to record the predator life table parameters. Data obtained from the experiments were recorded to determine the development of age-related life tables for each temperature that used.

\section{Statistical analyzes}

Life table parameters of the predator were calculated by using RmStat-3 software (Özgökçe \& Karaca, 2010) according to Euler-Lotka equation (Birch, 1948) and were evaluated separately. Tukey multiple comparison test was used for comparison of the periods with SPSS (ver. 17) at the significant difference $p<0.05$ level. To calculate the parameters, several equations were used which were: 
$\sum_{y=x}\left(e^{r_{m} \cdot y} \cdot l_{y} \cdot m_{y}\right)$

Reproductive value $\left(\mathrm{V}_{\mathrm{x}}\right) V_{x}=\frac{}{l_{x, e^{-r_{m}, x}}}$

(Imura, 1987);

Expected remaining life time $\left(\mathrm{E}_{\mathrm{x}}\right) E_{x}=\frac{\sum_{y=x} \frac{l_{y}+l_{y+1}}{2}}{l_{x}} \quad$ (Southwood, 1978; Carey, 1993);

Stable age distribution $\left(\mathrm{C}_{\mathrm{x}}\right) C_{x}=\frac{l_{x} \cdot e^{-\tau_{x x} \cdot x}}{\sum_{x=0}\left(l_{x} \cdot e^{-r_{x}-x}\right)}$

(Birch, 1948);

Net Production Rate $\left(\mathrm{R}_{0}\right) R_{0}=\sum l_{x} . m_{x}$

(Birch, 1948);

Intrinsic Rate of Increase ( $\left.\mathrm{r}_{\mathrm{m}}\right) \sum e^{\left(-r_{m}-x\right)} l_{x} \cdot m_{x}=1$

(Birch, 1948);

Mean Generation Time $\left(\mathrm{T}_{0}\right) T_{o}=\frac{\ln R_{0}}{r_{m}}$

(Birch, 1948);

Total Productivity Rate (GRR) GRR $=\sum m_{x}$

(Birch, 1948);

Daily maximum reproductive value $(\lambda) \lambda=e^{r_{m}}$

(Birch, 1948);

Doubling time $\left(\mathrm{T}_{2}\right) T_{2}=\frac{\ln 2}{r_{m}}$

(Kairo and Murphy, 1995).

The pseudo-rmij values were calculated with according to the Jackknife method (Meyer et al., 1986; Özgökçe \& Atlihan, 2004) including the use of intrinsic rate of increase values that were calculated for these populations in comparison tests.

\section{Results}

Daily and total numbers of eggs of the predator $R$. lophanthae at different temperatures were significantly different according to Tukey multiple comparison tests, which were $\left(F_{D N E}=73.62 ; D F=9 ; P \leq 0.001 ; F_{T N E}=\right.$ 18.75; $\mathrm{DF}=9 ; \mathrm{P} \leq 0.001)$. Daily numbers of eggs increased with increasing the temperature degree until $28^{\circ} \mathrm{C}$, afterwards, the numbers of eggs decreased. The lowest daily number of eggs was $0.70 \pm 0.14$ eggs, calculated at $14^{\circ} \mathrm{C}$. While the highest daily number of eggs $\left(11.17 \pm 0.65\right.$ eggs) was recorded at $28^{\circ} \mathrm{C}$. In other words, the lowest total numbers of eggs were $64.2 \pm 12.1$ and $30.9 \pm 3.72$ eggs, respectively, were determined at 14 and $32^{\circ} \mathrm{C}$; while the highest total numbers of eggs (479.7 \pm 54.6 eggs) were found at 
$28^{\circ} \mathrm{C}$. Both of daily and total egg numbers were obtained at $28^{\circ} \mathrm{C}$ and were found statistically different from the number of eggs that recorded at other temperature degrees (Fig. 1).

At the end of the experiment, life table parameters of $R$. lophanthae were determined at 10 different temperature degrees. According to the statistical analyzes, Intrinsic Rate of Increase $\left(r_{m}\right)$ were 0.016 , $0.022,0.030,0.052,0.056,0.068,0.120,0.142,0.132$ and 0.021 females/female/day, respectively. The differences of pseudo-rmij values were determined according to Tukey multiple comparison test. The Net Reproductive Rate $\left(R_{0}\right)$ were $7.082,9.514,11.960,50.906,54.150,49.525,56.883,80.944,31.149$ and $1.882 \mathrm{females} /$ female/generation, respectively. The lowest $R_{0}$ value $(1.882)$ was calculated at $32^{\circ} \mathrm{C}$, whereas the highest value of $R_{0}(80.944)$ was found at $28^{\circ} \mathrm{C}$. Mean Generation Time $\left(T_{0}\right)$ was calculated and the results recorded were 125.966, 104.602, 84.009, 75.742, 71.511, 57.568, 33.801, 30.866, 25.978 and 30.759 days, respectively (Table 1). The results of Total Productivity Rate (GRR) recording the highest value, was $303.751 \mathrm{eggs} / \mathrm{female}$ at $28^{\circ} \mathrm{C}$. The shortest period of Doubling Time (T2) was (4.869 days) and calculated at $28^{\circ} \mathrm{C}$; while the longest period value was found ( 44.604 days) at $14^{\circ} \mathrm{C}$. The lowest Daily Maximum Reproductive Value $(\lambda)$ was $\left(1.016\right.$ individual/female/day) at $14^{\circ} \mathrm{C}$, while the highest value was 1.153 individual/female/day at $28^{\circ} \mathrm{C}$ (Table 1$)$. 
Table 1

Life table parameters of Rhyzobius lophanthae at different temperatures

\begin{tabular}{|c|c|c|c|c|c|}
\hline & $14^{\circ} \mathrm{C}$ & $16^{\circ} \mathrm{C}$ & $18^{\circ} \mathrm{C}$ & $20^{\circ} \mathrm{C}$ & $22^{\circ} \mathrm{C}$ \\
\hline \multirow[t]{4}{*}{ Intrinsic rate of increase, $r_{m}$} & 0.016 & 0.022 & 0.030 & 0.052 & 0.056 \\
\hline & \pm & \pm & \pm & \pm & \pm \\
\hline & 0.000052 & 0.000049 & 0.000074 & 0.000133 & 0.000126 \\
\hline & j & h & $\mathrm{g}$ & $f$ & e \\
\hline \multirow[t]{4}{*}{ Pseudo-r ${ }_{\mathrm{mij}}$} & 0.0156 & 0.0219 & 0.0288 & 0.0528 & 0.0563 \\
\hline & \pm & \pm & \pm & \pm & \pm \\
\hline & 0.00273 & 0.00258 & 0.00364 & 0.00398 & 0.00402 \\
\hline & e & de & cde & bcd & $\mathrm{bc}$ \\
\hline \multirow[t]{4}{*}{ Net reproductive rate, $\mathbf{R}_{\mathbf{0}}$} & 7.082 & 9.514 & 11.960 & 50.906 & 54.150 \\
\hline & \pm & \pm & \pm & \pm & \pm \\
\hline & 0.0436 & 0.0481 & 0.0682 & 0.507 & 0.477 \\
\hline & 1 & $\mathrm{~h}$ & $\mathrm{~g}$ & $d$ & c \\
\hline \multirow[t]{4}{*}{ Mean generation time, $T_{0}$} & 125.940 & 104.610 & 84.015 & 75.758 & 71.509 \\
\hline & \pm & \pm & \pm & \pm & \pm \\
\hline & 0.0327 & 0.0368 & 0.0349 & 0.0818 & 0.0604 \\
\hline & a & b & c & $d$ & e \\
\hline \multirow[t]{4}{*}{ Total productivity rate, GRR } & 34.865 & 39.210 & 48.216 & 201.780 & 209.360 \\
\hline & \pm & \pm & \pm & \pm & \pm \\
\hline & 0.126 & 0.103 & 0.137 & 0.755 & 0.514 \\
\hline & I & $\mathrm{h}$ & $g$ & c & $\mathrm{b}$ \\
\hline \multirow[t]{4}{*}{ Doubling time, $\mathrm{T}_{2}$} & 44.648 & 32.206 & 23.482 & 13.370 & 12.423 \\
\hline & \pm & \pm & \pm & \pm & \pm \\
\hline & 0.157 & 0.0750 & 0.0623 & 0.0347 & 0.0283 \\
\hline & a & c & $d$ & e & e \\
\hline
\end{tabular}

Different letters on the same parameters and same line show that there is a statistical difference according to Tukey, $\mathrm{p}<0.05$. 


\begin{tabular}{|c|c|c|c|c|c|}
\hline & $14^{\circ} \mathrm{C}$ & $16^{\circ} \mathrm{C}$ & $18^{\circ} \mathrm{C}$ & $20^{\circ} \mathrm{C}$ & $22^{\circ} \mathrm{C}$ \\
\hline Daily maximum & 1.0157 & 1.0218 & 1.0300 & 1.0532 & 1.0574 \\
\hline \multirow[t]{3}{*}{ reproductive value, $\boldsymbol{\lambda}$} & \pm & \pm & \pm & \pm & \pm \\
\hline & 0.000052 & 0.000050 & 0.000077 & 0.000140 & 0.000133 \\
\hline & j & $\mathrm{h}$ & $\mathrm{g}$ & $f$ & $\mathrm{e}$ \\
\hline \multirow[t]{2}{*}{$\mathbf{N}$} & 54 & 54 & 50 & 31 & 51 \\
\hline & $24^{\circ} \mathrm{C}$ & $26^{\circ} \mathrm{C}$ & $28^{\circ} \mathrm{C}$ & $30^{\circ} \mathrm{C}$ & $32^{\circ} \mathrm{C}$ \\
\hline \multirow[t]{4}{*}{ Intrinsic rate of increase, $r_{m}$} & 0.068 & 0.120 & 0.142 & 0.132 & 0.021 \\
\hline & \pm & \pm & \pm & \pm & \pm \\
\hline & 0.000113 & 0.000133 & 0.000128 & 0.000263 & 0.000261 \\
\hline & $d$ & c & a & $b$ & 1 \\
\hline \multirow[t]{4}{*}{ Pseudo-r $_{\text {mij }}$} & 0.0684 & 0.1209 & 0.1419 & 0.1336 & 0.0235 \\
\hline & \pm & \pm & \pm & \pm & \pm \\
\hline & 0.00431 & 0.00652 & 0.00757 & 0.01050 & 0.01300 \\
\hline & b & a & a & a & cde \\
\hline \multirow[t]{4}{*}{ Net reproductive rate, $\mathbf{R}_{\mathbf{0}}$} & 49.525 & 56.883 & 80.944 & 31.149 & 1.882 \\
\hline & \pm & \pm & \pm & \pm & \pm \\
\hline & 0.313 & 0.237 & 0.313 & 0.198 & 0.0140 \\
\hline & e & $b$ & a & $f$ & j \\
\hline \multirow[t]{4}{*}{ Mean generation time, $T_{0}$} & 57.570 & 33.805 & 30.862 & 25.978 & 30.775 \\
\hline & \pm & \pm & \pm & \pm & \pm \\
\hline & 0.0354 & 0.0087 & 0.0112 & 0.0089 & 0.0138 \\
\hline & $f$ & g & $\mathrm{h}$ & 1 & $\mathrm{~h}$ \\
\hline \multirow[t]{4}{*}{ Total productivity rate, GRR } & 166.180 & 177.799 & 303.751 & 105.660 & 12.622 \\
\hline & \pm & \pm & \pm & \pm & \pm \\
\hline & 0.582 & 0.138 & 0.435 & 0.254 & 0.0420 \\
\hline & e & $d$ & $a$ & $f$ & $\mathrm{j}$ \\
\hline
\end{tabular}

Different letters on the same parameters and same line show that there is a statistical difference according to Tukey, $\mathrm{p}<0.05$. 


\begin{tabular}{|c|c|c|c|c|c|}
\hline & $14^{\circ} \mathrm{C}$ & $16^{\circ} \mathrm{C}$ & $18^{\circ} \mathrm{C}$ & $20^{\circ} \mathrm{C}$ & $22^{\circ} \mathrm{C}$ \\
\hline \multirow[t]{4}{*}{ Doubling time, $\mathbf{T}_{2}$} & 10.228 & 5.800 & 4.869 & 5.239 & 34.167 \\
\hline & \pm & \pm & \pm & \pm & \pm \\
\hline & 0.0173 & 0.0065 & 0.0044 & 0.0106 & 0.574 \\
\hline & $f$ & $\mathrm{~g}$ & $\mathrm{~h}$ & gh & $b$ \\
\hline \multirow{4}{*}{$\begin{array}{l}\text { Daily maximum } \\
\text { reproductive value, } \boldsymbol{\lambda}\end{array}$} & 1.0701 & 1.1270 & 1.1530 & 1.1415 & 1.0207 \\
\hline & \pm & \pm & \pm & \pm & \pm \\
\hline & 0.000121 & 0.000150 & 0.000148 & 0.000300 & 0.000265 \\
\hline & $d$ & c & a & $b$ & I \\
\hline $\mathbf{N}$ & 39 & 50 & 60 & 41 & 51 \\
\hline
\end{tabular}

The results of the values of Age-related survival rate $\left(I_{x}\right)$, Fertility rate $\left(m_{x}\right)$, Reproductive value $\left(V_{x}\right)$, Stable age distribution $\left(\mathrm{C}_{\mathrm{x}}\right)$ and Expected remaining life time $\left(\mathrm{E}_{\mathrm{x}}\right)$ of $R$. lophanthae calculated at different temperature degrees indicated that fertility rate and reproductive values that obtained at $28^{\circ} \mathrm{C}$ were $5.63 \pm 0.67$ and $30.60 \pm 3.05$, respectively, were determined at different temperature degrees according to the statistical analyzes $\left(F_{m x}=41.01 ; D F=9 ; P \leq 0.001 ; F_{V x}=34.32 ; D F=9 ; P \leq 0.001\right)$. Other values which were $\mathrm{I}_{\mathrm{x}}, \mathrm{C}_{\mathrm{x}}$ and $\mathrm{E}_{\mathrm{x}}$ of $R$. lophanthae were illustrated in Fig. 2.

\section{Discussion}

Stathas (2000) determined that the daily number of eggs ranged between 18 and 24 eggs when the predator $R$. lophanthae development was at $25^{\circ} \mathrm{C}$ and reported that the duration of the predator development from egg to adult was lower 24.82 days. Nar et al. (2009) studied the development of $R$. lophanthae at different temperatures $\left(15,20,25,30\right.$ and $\left.35^{\circ} \mathrm{C}\right)$ for a daily number of eggs that was calculated as 2.0, 7.0, 13.6, 7.1 and 3.6 eggs, respectively. Şimşek et al. (2016) determined the development of $R$. lophanthae on 3 different preys (Aspidiotus nerii, Chrysomphalus dictiyospermi, Aonidiella aurantii) and at $26^{\circ} \mathrm{C}$. The daily number of eggs was $5.53,5.16$ and 2.75 eggs depending on the predator feeding on preys, respectively. When compared with the studies conducted, it is seen that the data we obtained are close.

Stathas et al. (2005) determined that the development of $R$. lophanthae at $25^{\circ} \mathrm{C}$ and recorded an increase in the intrinsic rate and found 0.122 females/female/day. Nar et al. (2009) found $r_{m}$ values as 0.038 , $0.091,0.155,0.127$ and 0.103 females/female/day at different temperature degrees 15, 20, 25, 30 and $35^{\circ} \mathrm{C}$, respectively. Şimşek et al. (2016) determined that $r_{m}$ values on 3 different preys; $A$. nerii, $C$. 
dictiyospermi and $A$. aurantii at $26^{\circ} \mathrm{C}$ and the values were $0.120,0.061$ and 0.041 females/female/day, respectively. When the data obtained are examined, it is seen that the intrinsic rate of increase values obtained were close. It is thought that this is due to the fact that these studies were carried out at similar temperature values.

Stathas et al. (2005) found the net reproductive rate $\left(\mathrm{R}_{0}\right)$ of $R$. lophanthae at $25^{\circ} \mathrm{C}$ was 346.2 females/female/generation. Nar et al. (2009) indicated that the development of $R$. lophanthae at different temperature degrees $\left(15,20,25,30\right.$ and $\left.35^{\circ} \mathrm{C}\right)$ were $82.5,157.4,217.8,127.5$ and 53.3 females/female/generation, respectively. Şimşek et al. (2016) determined that the development of $R$. lophanthae fed on different preys which were $A$. nerii, $C$. dictiyospermi and $A$. aurantii at $26^{\circ} \mathrm{C}$ and $\mathrm{R}_{0}$ values were found as $36.027,12.520$ and 6.600 females/female/generation, respectively. It was observed that the net reproductive power value obtained in our study was higher than Şimşek et al. (2016) and lower than the other two studies. This difference is thought to be due to the difference in the number of repetitions.

Nar et al. (2009) calculated mean generation times $\left(T_{0}\right)$ of $R$. lophanthae at different temperatures 15,20 , 25,30 and $35^{\circ} \mathrm{C}$ and recorded the value of $\mathrm{T}_{0} 115.8,55.6,34.7,38.2$ and 37.1 days, respectively. In a follow up study, Şimşek et al. (2016) reported that examined the development of $R$. lophanthae fed on three different preys at $26^{\circ} \mathrm{C}$, calculated the value of $\mathrm{T}_{0}$ and recorded $30.005,41.151$ and 45.826 days, respectively. When the data obtained are examined, it is seen that the mean generation times obtained were close. This similarity is thought to be due to the same temperature values.

Şimşek et al. (2016) were calculated the total productivity rate as $125.542,65.111$ and 41.369 eggs/female, respectively when the predator $R$. lophanthae fed on three different preys $A$. nerii, $C$. dictiyorspermi, $A$. aurantii at $26^{\circ} \mathrm{C}$. It is seen that the value obtained in our study is higher than Şimşek et al. (2016). Stathas et al. (2005) were calculated the doubling time $\left(\mathrm{T}_{2}\right)$ of $R$. lophanthae to be 5.7 days at $25^{\circ} \mathrm{C}$. Nar et al. (2009), in their study which were examined the development of $R$. lophanthae at different temperature degrees $15,20,25,30$ and $35^{\circ} \mathrm{C}$, and calculated the $\mathrm{T}_{2}$ as $18.19,7.62,4.47,5.45$ and 6.47 days, respectively. However Şimşek et al. (2016) were calculated $\mathrm{T}_{2}$ of $R$. lophanthae fed on different preys A.nerii, $C$. dictiyospermi, $A$. aurantii at $26^{\circ} \mathrm{C}$ and their results were $5.803,11.286$ and 16.832 days, respectively. According to the data obtained, the doubling time was determined similar with Stathas et al. (2005) and Şimşek et al. (2016), while this value was determined by Nar et al. (2009) was observed to be lower. This difference between the values is thought to be due to the number of repetitions.

Stathas et al. (2005) mentioned in their study, the determination of $R$. lophanthae the development at $25^{\circ} \mathrm{C}$, which were calculated the daily maximum reproductive value ( 1.13 individual/female/day). Nar et al. (2009) calculated daily maximum reproductive value at different temperature degrees $15,20,25,30$ and $35^{\circ} \mathrm{C}$ and recorded $1.038,1.095,1.167,1.135$ and 1.113 individual/female/day, respectively, while Şimşek et al. (2016) found this value of $R$. lophanthae that fed on three different preys $A$. nerii, $C$. dictiyospermi, A. aurantii at $26^{\circ} \mathrm{C}$ were $1.127,1.063$ and 1.042 individual/female/day, respectively. When the results obtained were compared with these studies, it was observed that the values were close. 


\section{Conclusions}

The present study was carried out to select the optimum temperature for mass production of $R$. lophanthae as an efficient predator of citrus scale insect pests. Results demonstrated that the best development degree and maximum fecundity of the predator was at $28^{\circ} \mathrm{C}$.

\section{Declarations}

\section{Acknowledgements}

A part of this study was presented as oral presentation on XIV International Symposium of Scale Insect Studies, 13-16 June 2016, Catania, Italy. This study was supported by Research and Technology Department of Süleyman Demirel University in Isparta, Turkey (Project Number: 4636-D2-16)

\section{References}

1. Birch, L. C. (1948). The intrinsic rate of natural increase of an insect population. Journal of Animal Ecology, 17, 15-26.

2. Branco, B., Dalmau, L., Borges, I., \& Soares, O. (2017). Life-history traits of the predator Rhyzobius lophanthae reared on the scale Chrysomphalus dictyospermi.Bulletin Insectology 70(2), 231-235.

3. Carey, J. R. (1993). Applied demography for biologists with special emphasis on insects. Oxford University Press 211p.

4. Gao, G., Liu, S., Feng, L., Wang, Y., \& Lu, Z. (2020). Effect of temperature on predation by Harmonia axyridis (Pall.) (Coleoptera: Coccinellidae) on the walnut aphids Chromaphis juglandicola Kalt. and Panaphis juglandis (Goeze). Egyptian Journal of Biological Pest Control, 30, 137.

5. Hodek, l., \& Honek, A. (1996). Ecology of Coccinellidae. Kulver Academic Publisher, the Netherlands $464 p$.

6. Imura, O. (1987). Demographic attributes of Tribolium freeman Hinton (Coleoptera: Tenebrionidae). Applied Entomology and Zoology, 22(4), 449-455.

7. Kairo, M. T. K., \& Murphy, S. T. (1995). The life history of Rodolia iceryae Janson (Coleoptera:

Coccinellidae) and the potential for use in innoculative releases against /cerya pattersoni Newstead (Homoptera: Margarodidae) on coffee. Journal of Applied Entomology, 119, 487-491.

8. Kayahan, A., \& Karaca, i. (2020). Development periods of immature stages of Rhyzobius lophanthae blaisdell (coleoptera: coccinellidae) at different temperatures. Fresenius Environ Bulletin, 29(09A), 8168-8192.

9. Luhring, T. M., Vavra, J. M., Cressler, C. E., \& DeLong, J. P. (2019). Phenotypically plastic responses to predation risk are temperature dependent. Oecologia, 191, 709-719.

10. Mellado, J. J. S. (2011). Biological control of California red scale, Aonidiella aurantii (Hemiptera: Diaspididae): spatial and temporal distribution of natural enemies, parasitism levels and climate effects. PhD Thesis, Universitat Politécnica De Valencia, Instituto Agroforestal, Mediterráneo, 175p. 
11. Meyer, J. S., Ingersoll, C. G., McDonald, L. L., \& Boyce, M. S. (1986). Estimating uncertainty in population growth rates: Jackknife vs. Bootstrap techniques. Ecology, 67, 1156-1166.

12. Nar, E., Ulusoy, R., \& Karaca, ì. (2009). Farklı sıcaklıkların avcı böcek, Rhyzobius lophantae Blaisdell (Coleoptera: Coccinellidae)'nin gelişmesi üzerine etkisi. Süleyman Demirel Üniversitesi, Fen Dergisi 4(1), 59-74. (In Turkish)

13. Özgökçe, M. S., Karaca, İ. (2010). Yaşam Çizelgesi: Temel Prensipler ve Uygulamalar. Türkiye Entomoloji Derneği I. Çalıştayı, Ekoloji Çalışma Grubu, Isparta. (In Turkish)

14. Özgökçe, M. S., Atlıhan, R. (2004). Biological features and life table parameters of mealy plum aphid, Hyalopterus pruni on Different Apricot Cultivars. Phytoparasitica, 33(1),7-14.

15. Southwood, T. R. E. (1978). Ecological methods, with particular reference to the study of insect populations. Chapman and Hall, London, 524p.

16. Stathas, G. J. (2000). Rhyzobius lophanthae prey consumption and fecundity. Phytoparasitica, 28(3), 203-211.

17. Stathas, G. J., Eliopoulos, P. A., Kontodimas, D. C., \& Siamos, D. Th. (2002). Adult morphology and life cycle under constant temperature of the predator Rhyzobius lophanthae Blaisdell (Col., Coccinellidae). Journal of Pest Science, 75, 105-109.

18. Stathas, G. J., Kontodimas, D. C., Bouras, S. L., \& Economou, L. P. (2005). Life table parameters of Rhyzobius lophanthae Blaisdell (Coleoptera: Coccinellidae). Integrated Protection of Olive Crops, IOBC/WPRS Bulletin 28(9): 147-155.

19. Şimşek, B., Karaca, I.., \& Kayahan, A. (2016). Determination of developmental and life table parameters of Rhyzobius lophanthae Blaisdell (Coleoptera: Coccinellidae) on three armored scale insects (Hemiptera: Diaspididae). Redia XCIX, 219-223.

20. Uygun, N., \& Karaca, İ. (1998). Türkiye'de turunçgil zararlıları ve mücadelesi. Türkiye II. Turunçgil Kongresi. Adana, 7(22):39-46. (In Turkish)

\section{Figures}

\section{Figure 1}
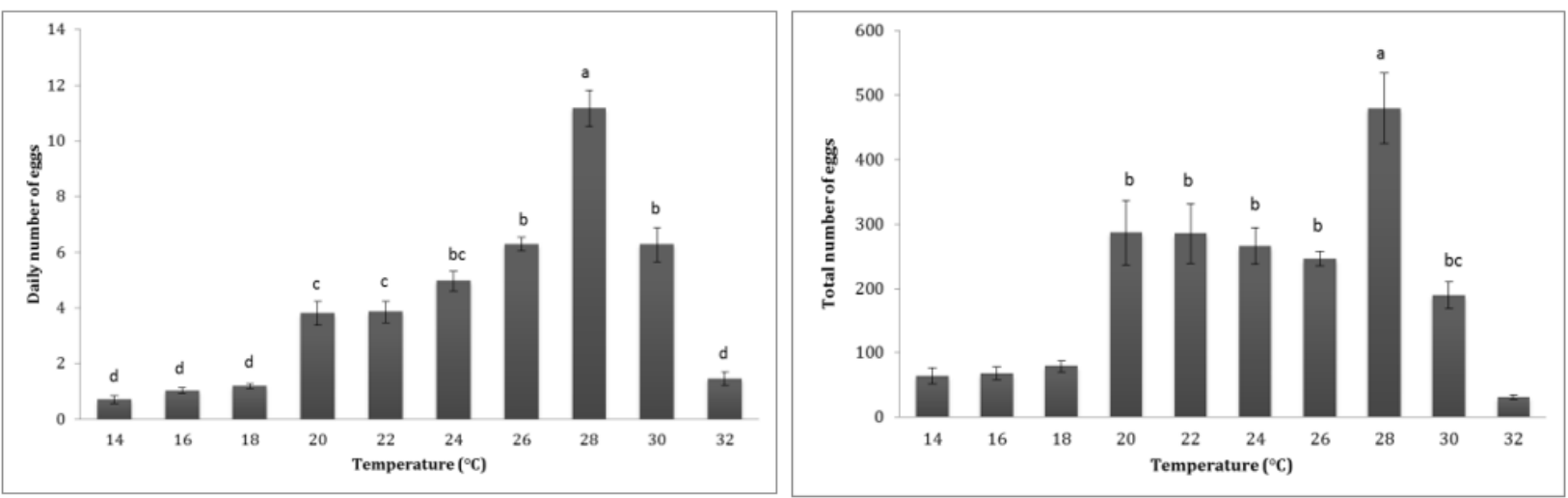
Figure 1

Daily and total numbers of eggs of Rhyzobius lophanthae at different temperatures. Different letters on different columns show that there is a statistical difference according to Tukey, $p<0.05\left(F_{D N E}=73.62 ; D F=\right.$ 9; $\left.P \leq 0.001 ; F_{T N E}=18.75 ; D F=9 ; P \leq 0.001\right)$ (DNE: Daily number of eggs; TNE: Total number of eggs; $D F$ : Degree of Freedom; SE: Standart Error)

\section{Figure 2}
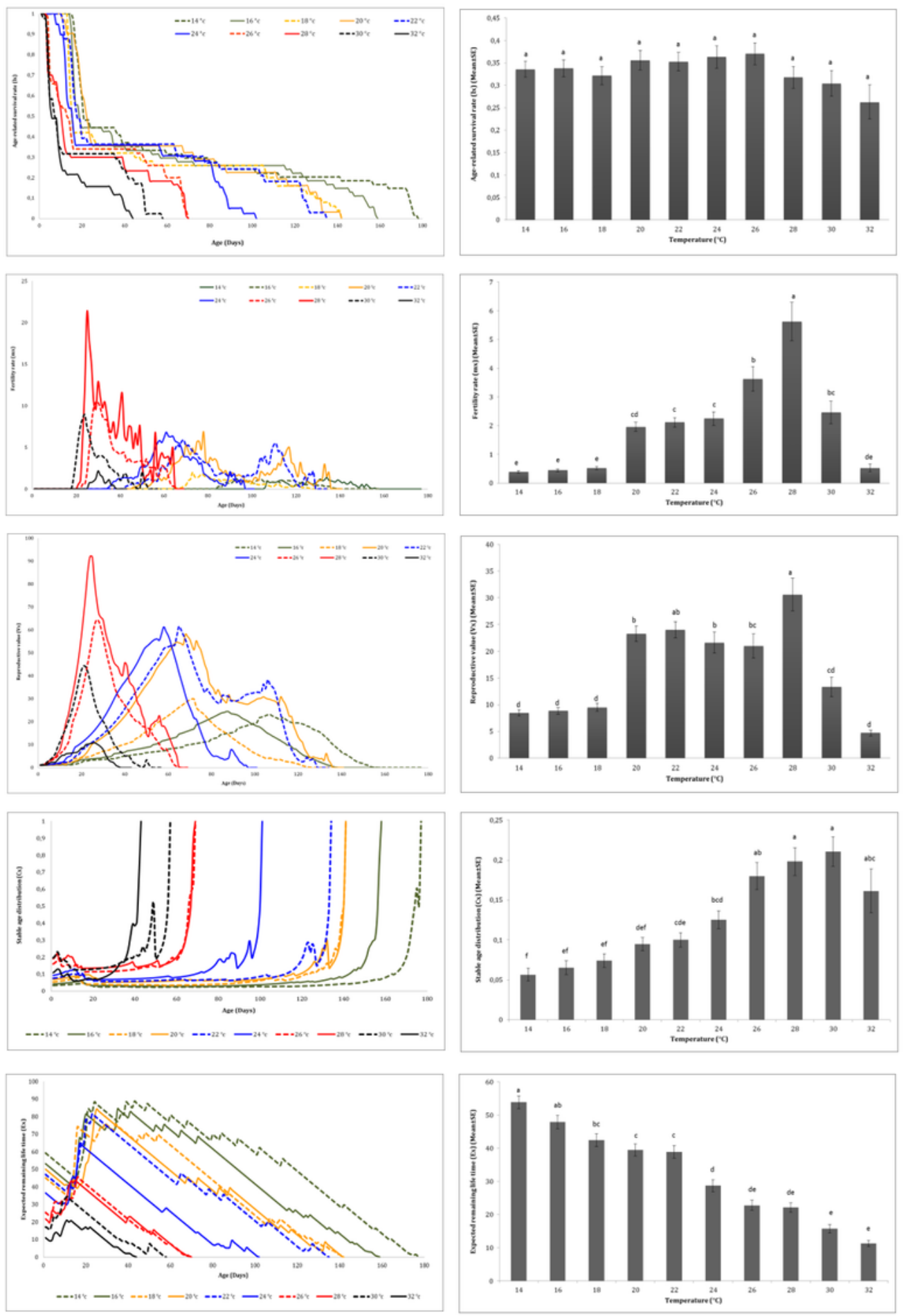


\section{Figure 2}

Age-related survival rate (Ix), Fertility rate (mx), Reproducitve value (Vx), Stable age distribution (Cx), Expected remaining life time (Ex), (From top to bottom). Different letters on different columns show that there is a statistical difference according to Tukey, $p<0.05\left(F_{I x}=1.17 ; D F=9 ; P=0.309 ; F_{m x}=41.01 ; D F=9\right.$; $\left.P \leq 0.001 ; F_{V x}=34.32 ; D F=9 ; P \leq 0.001 ; F_{C x}=21.61 ; D F=9 ; P \leq 0.001 ; F_{E x}=40.49 ; D F=9 ; P \leq 0.001\right)$ 